\title{
Use of Berlin Heart ventricular assist devices as a total artificial heart
}

Hideyuki Kato, MD, PhD, and Sanjiv K. Gandhi, MD, Vancouver, British Columbia, Canada

From the Division of Pediatric Cardiovascular and Thoracic Surgery, BC Children's Hospital, Vancouver, British Columbia, Canada.

Disclosures: Authors have nothing to disclose with regard to commercial support.

Received for publication Nov 28, 2017; revisions received Jan 25, 2018; accepted for publication March 4, 2018; available ahead of print March 28, 2018.

Address for reprints: Hideyuki Kato, MD, PhD, Division of Pediatric Cardiovascular and Thoracic Surgery, BC Children's Hospital, 4480 Oak St, Suite AB307, Vancouver, British Columbia, Canada V6H 3V4 (E-mail: hideyuki.kato@cw.bc.ca).

J Thorac Cardiovasc Surg 2018;156:743-5

$0022-5223 / \$ 36.00$

Copyright (C) 2018 by The American Association for Thoracic Surgery

https://doi.org/10.1016/j.jtcvs.2018.03.005

Pediatric use of the Berlin Heart EXCOR (BH; Berlin Heart $\mathrm{GmbH}$, Berlin, Germany) ventricular assist device (VAD) as a bridge to transplant (BTT) is commonplace. ${ }^{1}$ We describe a surgical technique that may overcome certain technical challenges.

BH VAD use in patients with single-ventricle physiology has been limited. ${ }^{2}$ The results are poor after stage I Norwood palliation. Single VAD support requires balancing the systemic and pulmonary circulations and is associated

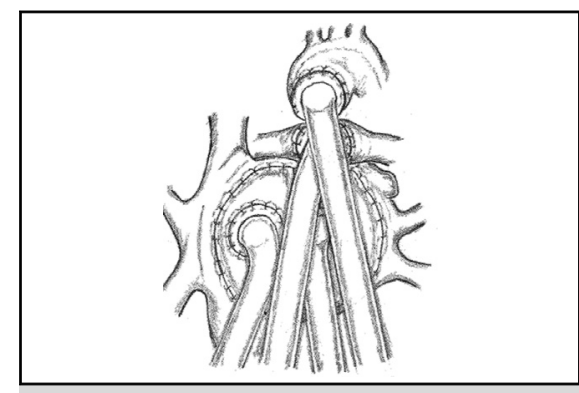

Biventricular assist device insertion as a total artificial heart.

\section{Central Message}

Anatomic challenges in patients with singleventricle anatomy mandated cardiectomy and biventricular VAD use as a successful bridge to transplant. This can be an option in select clinical situations.

See Editorial Commentary page 746.

See Editorial page 741 .
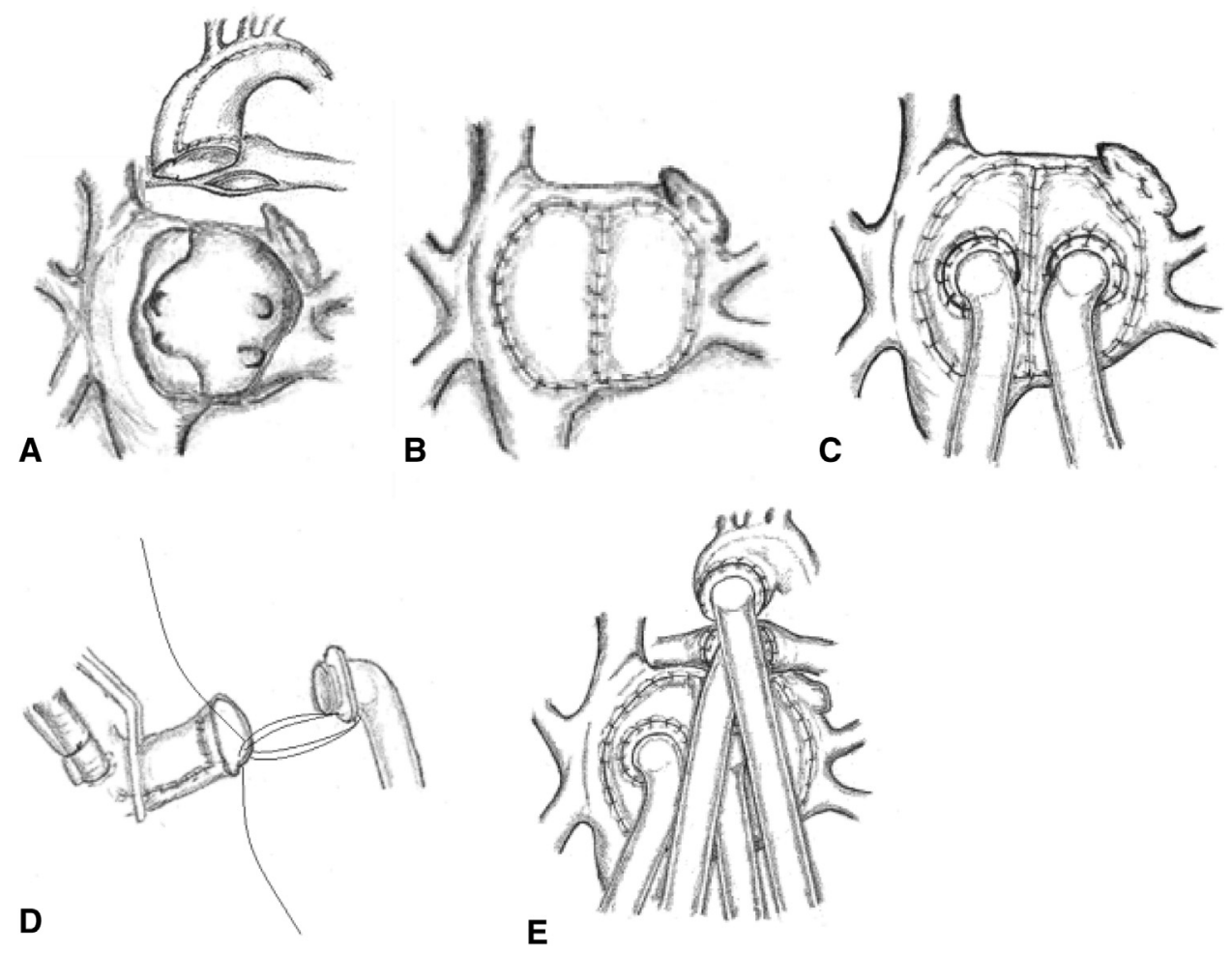

FIGURE 1. Cardiectomy and BiVAD insertion technique. A, After cardiectomy, with cuffs left of atria, neoaorta, and main pulmonary artery. B, Atrial cavity reconstruction with bovine pericardial patches. C, Atrial cannulation. D, Arterial cannulation. E, After BiVAD insertion. 
with increased complications. ${ }^{3}$ Support with biventricular assist device (BiVAD) placement mirrors normal cardiovascular physiology. Technical challenges relate to small thoracic capacity and enlarged cardiac size. Explantation of the native heart allows the use of BiVADs as a total artificial heart (TAH). ${ }^{4}$ We report the cases of 2 infants successfully supported to heart transplantation (HT) after cardiectomy and BH BiVAD placement.

\section{TAH SURGICAL TECHNIQUE}

Cardiopulmonary bypass was initiated with aortic and neoaortic and bicaval cannulation. Cardiectomy was performed, leaving cuffs of ascending aorta, main pulmonary artery, and posterior right and left atria. After resection of the atrial septum to equalize atrial size, the atria were reconstructed with bovine pericardium (Figure 1, $A$ and $B$ ). Two 6-mm atrial cannulas were shortened, and new tip side holes were created to optimize venous drainage. These modified cannulas were sewn to openings made in the atrial patches (Figure 1,C). Two 6-mm arterial cannulas were then anastomosed end to end to both the aorta and the pulmonary artery (Figure 1,D). All cannulas were tunneled, and 10-mL left and right VAD blood pumps were attached (Figure 1,E). The pumps were run separately. Rates were set with the left VAD greater than the right VAD by 5 beats and to achieve a cardiac index of at least $3 \mathrm{~L} / \mathrm{min} / \mathrm{m}^{2}$.

\section{CLINICAL SUMMARIES}

\section{Case 1}

A female neonate had severe mitral stenosis and aortic atresia diagnosed. Echocardiography and cardiac catheterization demonstrated normal right ventricular function and coronary sinusoids without coronary stenoses (Figure 2, $A, B$, and $C$ ). An uneventful Norwood-Sano procedure was performed at 5 days. The patient was separated from bypass with robust hemodynamics. Several hours postoperatively, she had low cardiac output and was placed on extracorporeal membrane oxygenation support. Attempts at weaning from extracorporeal membrane oxygenation support were unsuccessful because of unmanageable sinusoidal runoff, manifested by low diastolic blood pressures. The patient was transitioned to $\mathrm{BH}$ TAH on postoperative day 8 as a BTT (Figure 2,D). Her clinical condition improved. After 6 days of TAH support, while preparing for extubation, a suitable donor was identified, and the patient underwent HT.

HT was complicated by primary graft dysfunction requiring extracorporeal membrane oxygenation support for 6 days and a severe acute kidney injury after the initiation of tacrolimus. The patient died 18 days after HT.

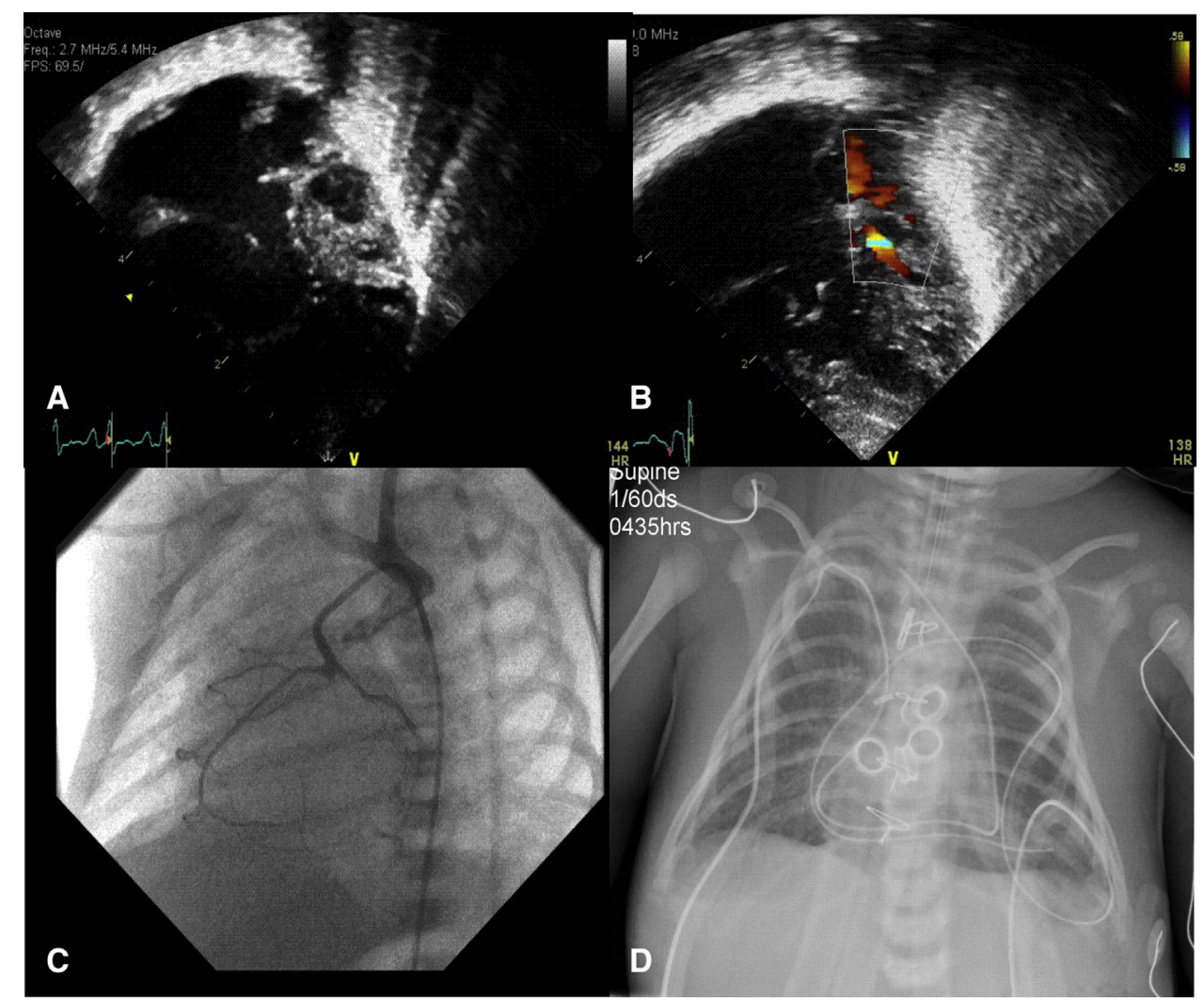

FIGURE 2. Case 1 preoperative and postoperative images. A, Preoperative transthoracic echocardiography. B, Preoperative transthoracic echocardiography with color Doppler (color shows large sinusoidal communication). C, Preoperative angiography. D, Postoperative chest radiography. 


\section{Case 2}

A 14-week-old female infant presented with end-stage heart failure secondary to an idiopathic noncompaction cardiomyopathy. Despite maximal medical support, her condition deteriorated, and she was listed for HT. She was transitioned to BH TAH support as a BTT at 19 weeks of age.

Massive right atrial and ventricular enlargement impeded placement of the pulmonary artery and aortic cannulas, necessitating the TAH approach. Hemodynamics were excellent after weaning from bypass. The patient's postoperative course was complicated by mediastinal bleeding requiring reexploration. The patient was extubated on postoperative day 1 and was quickly transferred to the regular ward. Her VAD course was complicated by a chylothorax, which was treated medically, and 2 episodes of unexplained late pleural bleeding, which required thoracotomies. Her BiVADs functioned well. After 105 days, she underwent uncomplicated HT. She remains well at 3-year follow-up.

\section{DISCUSSION}

The Berlin Heart EXCOR VAD is now a common successful BTT device for children. Certain anatomic and physiologic situations, however, remain challenging. Mediastinal space limitations are an impediment to accommodating BiVADs. The survival for infants with single-ventricle anatomy is poor. ${ }^{2}$ Small size, high pulmonary vascular resistance in infancy, and difficulty managing a parallel circulation with a single VAD all pose problems. BiVAD support is optimal to achieve a stable circulation as a bridge, and the use of BiVADs as a TAH is an option in select circumstances. There is precedent for this approach in older children. ${ }^{4}$
Attention to technical details is vital for procedural success. Generous atrial cavities with patch augmentation optimize adequate drainage, and modified cannulas perfect the geometric alignment. These details ensure laminar flow, promote optimal VAD function, and minimize thromboembolic complications. With the extensive reconstruction required, meticulous hemostasis is vital. In addition, left atrial cannulation increases risk for thrombotic and subsequent neurologic complications. ${ }^{5}$ Complete excision of the left atrial appendage and left ventricle may mitigate this risk.

\section{CONCLUSIONS}

We present the cases of 2 infants who required BiVAD support as a BTT. The decision to undertake cardiectomy and BiVAD use as a TAH was stimulated by anatomic and physiologic challenges. This novel approach was successful in supporting the children until HT and is an option in very select clinical situations.

\section{References}

1. Eghtesady P, Almond CS, Tjossem C, Epstein D, Imamura M, Turrentine M, et al; Berlin Heart Investigators. Post-transplant outcomes of children bridged to transplant with the Berlin heart EXCOR pediatric ventricular assist device. Circulation. 2013;128(11 Suppl 1):S24-31.

2. Weinstein S, Bello R, Pizarro C, Fynn-Thompson F, Kirklin J, Guleserian K, et al The use of the Berlin heart EXCOR in patients with functional single ventricle. J Thorac Cardiovasc Surg. 2014;147:697-704; discussion 704-5.

3. Jordan LC, Ichord RN, Reinhartz O, Humpl T, Pruthi S, Tjossem C, et al. Neurological complications and outcomes in the Berlin heart EXCOR ${ }^{\circledR}$ pediatric investigational device exemption trial. J Am Heart Assoc. 2015;4:e001429.

4. Valeske K, Yerebakan C, Mueller M, Akintuerk H. Urgent implantation of the Berlin heart Excor biventricular assist device as a total artificial heart in a patient with single ventricle circulation. J Thorac Cardiovasc Surg. 2014;147:1712-4.

5. Timms D, Gregory S, Hsu PL, Thomson B, Pearcy M, McNeil K, et al. Atrial versus ventricular cannulation for a rotary ventricular assist device. Artif Organs. 2010;34:714-20. 